\title{
Оценка влияния введения фторопластовых \\ вибропоглощающих элементов \\ на физико-механические \\ свойства полимерных \\ композиционных материалов
}

\section{Evaluation of the influence \\ of fluoropolymer-based \\ vibration damping elements \\ on mechanical properties \\ of polymer composite materials}

\author{
А. Н. Шумакова ${ }^{1-2}$, Е. А. Данилов ${ }^{1}$, \\ А. Р. Гареев ${ }^{1}$, А. А. Белогорлов ${ }^{2}$ \\ ${ }^{1}$ АО «Научно-исследовательский институт конструкционных \\ материалов на основе графита «НИИграфит» \\ (АО «НИИграфит»), Москва, Россия \\ ${ }^{2}$ Национальный исследовательский ядерный \\ университет «МИФИ», Москва, Россия
}

\author{
A. N. Shumakova ${ }^{1-2}$, E. A. Danilov', \\ A. R. Gareyev', A. A. Belogorlov ${ }^{2}$ \\ ${ }^{1}$ Research Institute \\ for Graphite-Based Structural Materials \\ "NIlgrafit", Moscow, Russian Federation (JSC "NIIgrafit") \\ National Research \\ Nuclear University “MEPhl”
}

Поступила в редакцию 18.06.2019, принята к печати 25.09.2019

\section{Абстракт}

В работе исследовано влияние способа выкладки и введения фторопластовых пленок на физико-механические свойства полимерных композиционных материалов на основе углепластиковых препрегов, предназначенных для изготовления конструкций с эффектом пассивного вибропоглощения. Сделан краткий обзор тематической литературы. Оценка эффективности поглощения механических колебаний проводилась по измерению динамического модуля упругости резонансным методом и путем определения скорости распространения звука в среде. Установлена предпочтительность резонансного метода определения. Результаты работы могут быть непосредственно использованы при изготовлении корпусов элементов управления из углепластиков.

\section{Abstract}

In the present paper the influence of layout scheme and fluoropolymer-based film introduction on mechanical properties of carbon fiberreinforced prepreg-based polymer composite materials intended for application in passive vibration damping systems. A short review of the current technical literature is made. Evaluation of vibration damping was made through dynamic modulus measurement by both resonance and acoustic speed-based techniques. Advantages of the former technique are shown. Results of the study may be directly used in carbon fiber reinforced polymer-based operator panels.

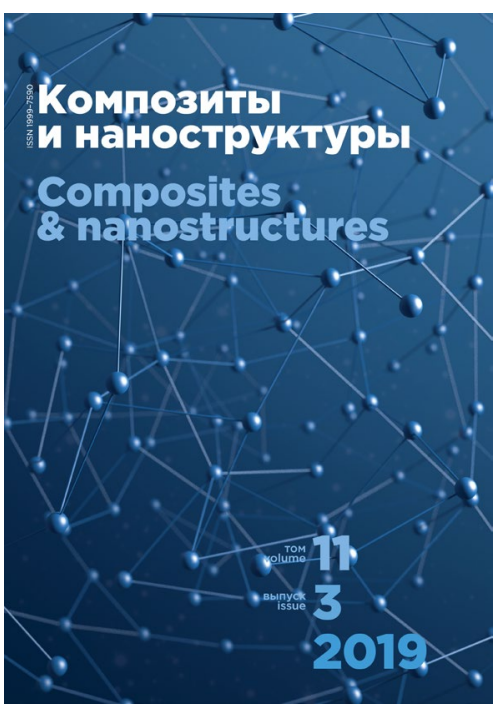

